\title{
Cellular Transport of L-Histidine in Hartnup Disease
}

\author{
Sverre Halvorsen, Olof Hygstedt, Rudolf Jagenburg, and \\ OtTaR SjaAstad \\ From Children's Hospital and Pediatric Research Institute, Rikshospitalet, \\ Oslo, Norway, and the Departments of Medical Biochemistry and Clinical \\ Chemistry, University of Gothenburg, Gothenburg, Sweden
}

\begin{abstract}
A в S TRA C T The urinary excretion, the intestinal absorption, and the elimination of histidine from blood were studied in two patients with Hartnup disease. On standard diet the patients lost a great proportion of the dietary histidine in the urine, whereas the fecal loss was negligible. A high oral dose of L-histidine gave only a slight increase in plasma histidine and no increase in fecal histidine, but a considerable increase in the urinary histidine output. Intravenously administered L-histidine was eliminated more rapidly than in controls. The lack of increase in plasma histidine after the oral loading may be explained by the rapid elimination from the blood. This was mainly due to a rapid cellular uptake of histidine which is supposed to be a normal reaction of histidine-deprived cells. Thus the only obvious defect in the histidine transport in Hartnup disease is the reabsorption defect in the renal tubules. A generally impaired cellular transport of L-histidine is improbable.
\end{abstract}

\section{INTRODUCTION}

Hartnup disease is an inherited disorder biochemically characterized by a specific aminoaciduria supposedly due to a defect in the membrane transport of a group of monoamino-monocarboxylic acids (1). Great interest has been focused on the metabolism of tryptophan. This amino acid seems to be poorly absorbed not only from the renal tubules but also from the intestine (2-4). A defective intestinal absorption of the other monoamino-monocarboxylic acids has been suggested but has not yet been proved ( $c f .4$ ). Histidine appears to be the amino acid which is reabsorbed to the smallest extent in the renal tubules in Hartnup disease (5). This amino acid therefore ought to be suitable for further studies of the suggested amino acid malabsorption in this disease.

The urinary and fecal excretion of histamine metabolites in this disorder was previously investigated (6).

Received for publication 30 January 1968 and in revised form 11 March 1969.
The aim of the present investigation was to study the intestinal absorption of orally administered L-histidine. The increase in the plasma histidine and the fecal and urinary loss of histidine were used as parameters of absorption. The rate of disappearance of histidine from plasma was also estimated after intravenous loading.

\section{METHODS}

The two patients studied have previously been described by Halvorsen and Halvorsen (7) and only a short summary of the histories will be presented. N. A., a female, was $19 \mathrm{yr}$ old at the time of the present study. From the first summer of her life she had an itching rash on areas exposed to light, mainly the hands, forearms, and face. In the spring 1960 the dermatitis was more severe and in addition she complained of dizziness, diplopia, stiffness, and pains in the chest. She was restless, nervous, and showed signs of confusion. Laboratory investigations revealed generalized aminoaciduria, except for proline, and increased excretion of indican, indole acetyl-glutamine, and indole acryl-glycine. She was given a combined vitamin B preparation with $40-60 \mathrm{mg}$ nicotinamide daily and she continued on this therapy until late fall 1967. The symptoms subsided rapidly on this therapy and she was free of symptom until spring 1968 when the dermatitis again was noticed and therapy reinstituted. E. A., a brother of N. A., was $15 \mathrm{yr}$ old at the time of the study. At the age of $5 \mathrm{yr}$ he had series of spells during which he was stiff and out of contact, but still conscious. Laboratory investigations revealed the same generalized aminoaciduria and indoluria as his sister. From the age of $5 \mathrm{yr}$ he had every spring and summer an itching rash on the face, forearms, hands, and legs. He has received the same vitamin B therapy as his sister continuously from the age of $9 \mathrm{yr}$ and he has had no symptoms since that time. The aminoaciduria and indoluria have persisted in both cases during the therapy.

Oral loading. The patients and three male controls ( $\mathrm{S}$, $\mathrm{H}$, and $\mathrm{T}$ ), aged 57,48 , and $42 \mathrm{yr}$, were hospitalized and kept on a standard diet for 5 days, starting 2 days before the loading. Three meals were given per day, at $8: 15$ a.m., 12:15 p.m., and 5:30 p.m. Each meal consisted of whole meal bread $(30-40 \mathrm{~g})$, butter $(10 \mathrm{~g})$, cheese $(10 \mathrm{~g})$, and $400 \mathrm{ml}$ of milk ( $4 \% \mathrm{fat}$ ). On the day of loading, L-histidine monohydrochloride monohydrate (Sigma Chemical Co., St. Louis, Mo.), 0.7 mmoles $/ \mathrm{kg}$ body weight, was administered at 8 a.m. (zero time), together with approximately $100 \mathrm{ml}$ of tap water. 
TABLE I

Plasma Concentration, Urinary Excretion, and Renal Clearance of Free Amino Acids in Two Patients with Hartnup Disease

\begin{tabular}{|c|c|c|c|c|c|c|c|c|}
\hline & \multicolumn{4}{|c|}{ Plasma concn } & \\
\hline & \multirow[b]{2}{*}{ N. A. } & \multirow[b]{2}{*}{ E. A. } & \multicolumn{2}{|c|}{ Controls.* } & \multicolumn{2}{|c|}{ Urinary excretion } & \multicolumn{2}{|c|}{ Renal clearance } \\
\hline & & & Mean & $\pm 2 \mathrm{sD}$ & N. A. & E. A. & N. A. & E. A. \\
\hline & \multicolumn{4}{|c|}{ umoles/liter } & \multicolumn{2}{|c|}{ mmoles $/ 24 \mathrm{hr}$} & \multicolumn{2}{|c|}{$\begin{array}{c}m l / m i n \text { per } 1.73 \\
m^{2}, \text { body area }\end{array}$} \\
\hline Taurine & 55 & 65 & 79 & 62 & 0.14 & 0.45 & 2 & 5 \\
\hline Aspartic acid & $<10$ & $<10$ & $<10$ & & $<0.20$ & $<0.20$ & - & - \\
\hline Threonine & 67 & 83 & 90 & 44 & 4.70 & 3.91 & 45 & 31 \\
\hline Serine & 135 & 151 & 105 & 36 & 12.00 & 10.00 & 56 & 43 \\
\hline Glutamine & 580 & 623 & 550 & 154 & 21.60 & 19.70 & 24 & 21 \\
\hline Proline & 138 & 141 & 140 & 34 & $<0.20$ & $<0.20$ & $<1$ & $<1$ \\
\hline Glutamic acid & 22 & 24 & 37 & 22 & 0.33 & 0.53 & 9 & 14 \\
\hline Citrulline & 20 & 20 & 21 & 8 & 0.35 & 0.38 & 11 & 12 \\
\hline Glycine & 232 & 382 & 194 & 74 & 2.34 & 1.74 & 6 & 3 \\
\hline Alanine & 285 & 326 & 270 & 140 & 3.64 & 2.79 & 8 & 6 \\
\hline$\alpha$-amino- $n$-butyric acid & - & 16 & 17 & 12 & 0.42 & 0.37 & - & 15 \\
\hline Valine & 133 & 131 & 181 & 60 & 3.35 & 3.22 & 15 & 16 \\
\hline Cystine & - & - & + & - & $<0.20$ & $<0.20$ & - & - \\
\hline Methionine & 22 & 27 & 19 & 12 & 0.58 & 0.58 & 16 & 14 \\
\hline Isoleucine & 42 & 50 & 53 & 28 & 1.59 & 1.74 & 24 & 22 \\
\hline Leucine & 78 & 101 & 109 & 48 & 2.72 & 2.27 & 22 & 15 \\
\hline Tyrosine & 37 & 36 & 44 & 28 & 3.52 & 2.68 & 60 & 49 \\
\hline Phenylalanine & 31 & 46 & 51 & 28 & 1.22 & 1.33 & 24 & 19 \\
\hline Lysine + ornithine & 158 & 161 & 276 & 128 & 2.39 & 1.77 & 9 & 7 \\
\hline Histidine & 34 & 46 & 67 & 40 & 6.67 & 5.43 & 124 & 70 \\
\hline Arginine & 63 & 53 & 44 & 36 & $<0.10$ & $<0.10$ & $<1$ & $<1$ \\
\hline
\end{tabular}

* 10 healthy male subjects, age $21-36 \mathrm{hr}$.

Blood was withdrawn from the cubital vein at zero time and at $1,2,5$, and $8 \mathrm{hr}$ after loading. All blood samples were taken in heparinized tubes and centrifuged 10-20 min after the withdrawal. The plasma was immediately transferred to bottles and frozen. Urine was collected in 24-hr samples, in bottles containing $1.2 \mathrm{~N}$ hydrochloric acid. This secured a $\mathrm{pH}$ of less than 2 . Feces were collected for 5 days, i.e., 2 days before and 3 days after the loading. The specimen was ground thoroughly in a mortar as soon as possible after defecation. Aliquots were taken for determination of free amino acids and dry weight. For amino acid determination, an aliquot was mixed thoroughly with $0.02 \mathrm{M}$ hydrochloric acid to a total volume of $100-150 \mathrm{ml}$. The sample was centrifuged and filtered in a Buchner funnel with a slight suction. All samples of urine, plasma, and feces were kept frozen until the day of analysis.

Intravenous loading. Single-dose intravenous loading with L-histidine and tritium-labeled water (THO) was carried out on one patient (E. A.) and on four male controls (A, B, $C$, and D) aged 21-38 years. The loading was carried out in the morning after $12 \mathrm{hr}$ of fasting. All subjects were on an unrestricted diet. The histidine was given as a $5 \%$ solution, pH 7.4 (kindly supplied by AB Astra, Södertälje, Sweden), holding $8 \mu \mathrm{c} \mathrm{THO} / \mathrm{ml}$. Of this solution $0.8 \mathrm{ml} / \mathrm{kg}$ body weight, or maximum $50 \mathrm{ml}$ was rapidly given into the right cubital vein. The infusion time did not exceed $90 \mathrm{sec}$. Blood was withdrawn through a catheter inserted into the brachial ar- tery (patient E. A., controls C and D) or the left cubital vein (controls $C$ and $D$ ). Samples were taken before the infusion and afterwards at intervals of 2-15 min for $2 \mathrm{hr}$. Urine was collected separately for $2 \mathrm{hr}$ before the loading and for $4 \mathrm{hr}$ after the loading. All samples were handled as described above.

Chemical methods. Free amino acids in plasma and urine were estimated by the method of Spackman, Stein, and Moore (8), employing a $100 \mathrm{~cm}$ column for the neutral and acidic amino acids, and $15 \mathrm{~cm}$ column for the basic ones. The method did not permit determination of tryptophan. The resin used was Aminex-MS, Blen Q-150-S (Bio-Rad) for both columns. The plasma was deproteinized by picric acid as described by Stein and Moore (9).

The free amino acids in urine and feces were determined by two-dimensional paper chromatography (10). The acid fecal extract was passed through a small column $(0.9 \times 2$ $\mathrm{cm}$ ) of Dowex-2-X8 in the chloride form to remove chromogens. The column was then washed with $20 \mathrm{ml}$ of $0.02 \mathrm{M}$ hydrochloric acid, and the combined eluates were added to a column $(0.9 \times 5 \mathrm{~cm})$ of Dowex $50-\mathrm{X} 8$ in the hydrogen form. After washing with distilled water, the amino acids were eluated from the resin by $4 \mathrm{~m}$ ammonia. The eluate (about $5 \mathrm{ml}$ ) was lyophilized and the residue dissolved in a small volume of distilled water. Of this sample, a volume corresponding to $200 \mathrm{mg}$ of wet feces was applied to each chromatogram. 


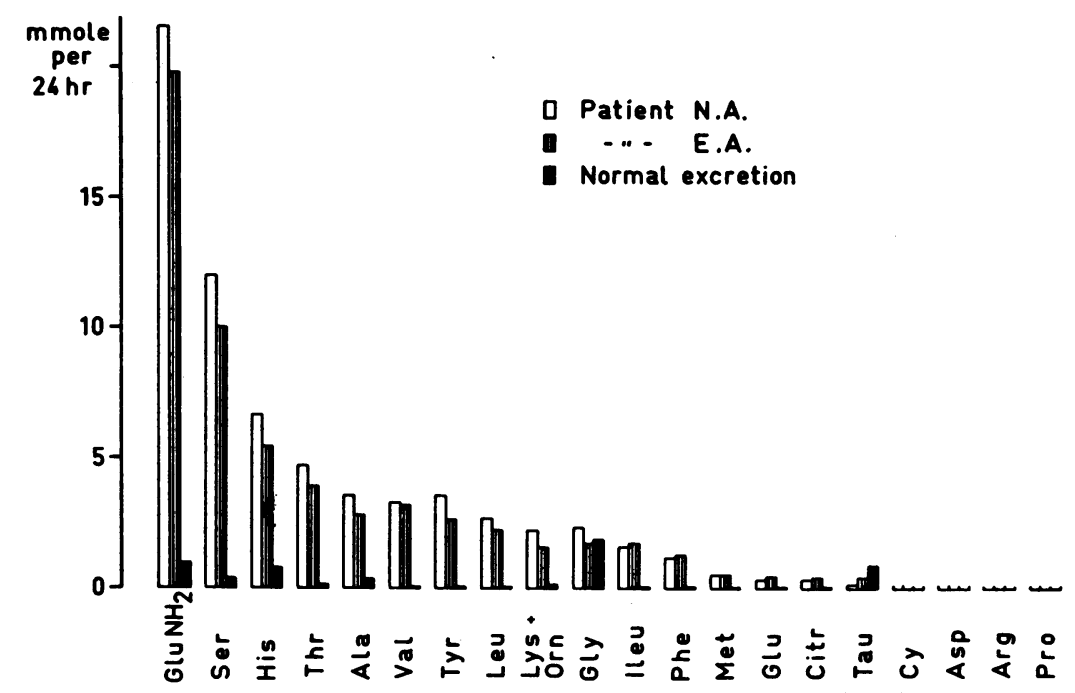

FIGURE 1 Urinary excretion of amino acids in two patients with Hartnup disease compared with normal excretion. The patients were on a standard diet containing 1500 calories, $55 \mathrm{~g}$ protein, and $1.4 \mathrm{~g}$ ( $9 \mathrm{mmole})$ histidine/day.

Amino nitrogen, total nitrogen, and creatinine in urine were measured by the standard methods used in our laboratory $(10)$.

Tritium was analyzed in a Packard Tri-Carb liquid scintillation spectrometer (11). The plasma water was obtained by vacuum sublimation (12). A regression line was calculated by the method of least squares from the plasma THO concentrations from 50 to $120 \mathrm{~min}$ after the loading. The
THO concentration at zero time, obtained from this line, was used for calculating the exchangeable body water.

\section{RESULTS}

Free amino acids in plasma, urine, and feces. The free amino acids in plasma, urine, and feces were determined when the patients were on a standard diet of

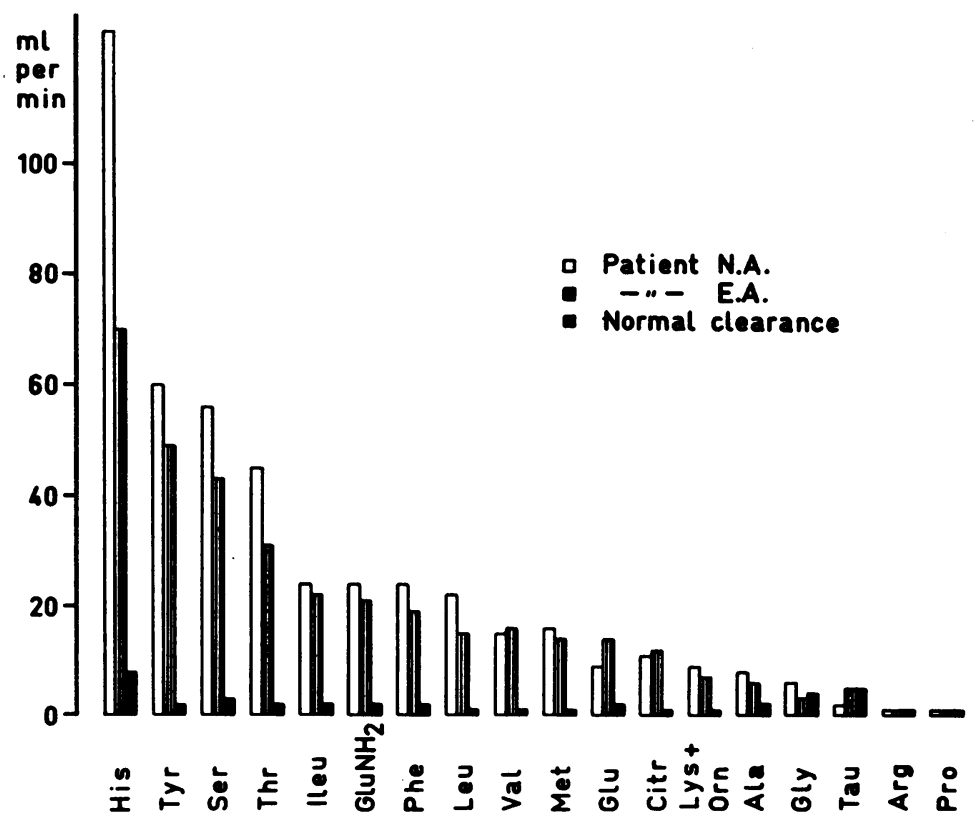

FIGURE 2 Renal clearance of amino acids in two patients with Hartnup disease compared with normal renal clearance. The clearance values were calculated from the $24 \mathrm{hr}$ urinary excretion and from the fasting plasma level. The patients were on a standard diet (see Fig. 1). 


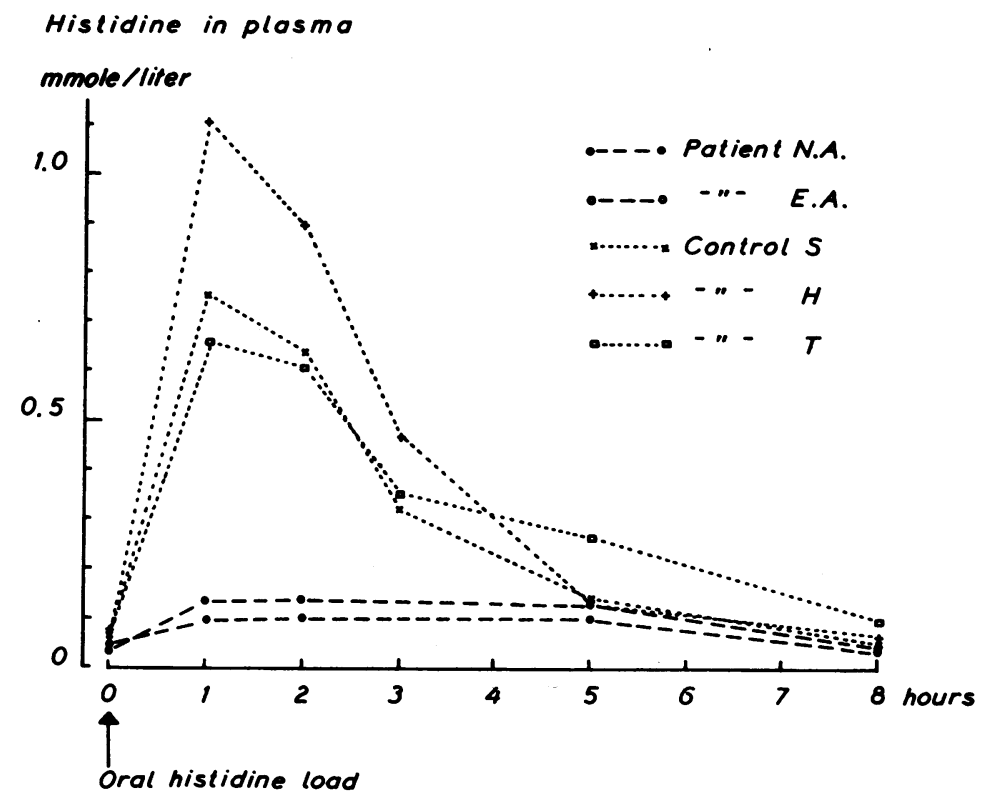

Figure 3 Plasma histidine level in two patients with Hartnup disease and three controls after oral loading with $\mathrm{L}$-histidine. The subjects were on a standard diet (see Fig. 1) and received a single dose of 0.7 mmoles histidine/kg body weight.

1500 calories, $55 \mathrm{~g}$ protein, and $1.4 \mathrm{~g}$ ( 9 mmole) histidine daily (13). In the patients, the fasting plasma amino acids were within the range (mean $\pm 2 \mathrm{SD}$ ) observed in 10 healthy male controls (Table I). However, the essential amino acids and histidine were below and the non- essential amino acids were above the mean control values.

The urinary excretion of most amino acids was highly increased (Table I). Of the total urinary nitrogen, $9 \%$ (E. A.) and $10 \%$ (N. A.), respectively, was
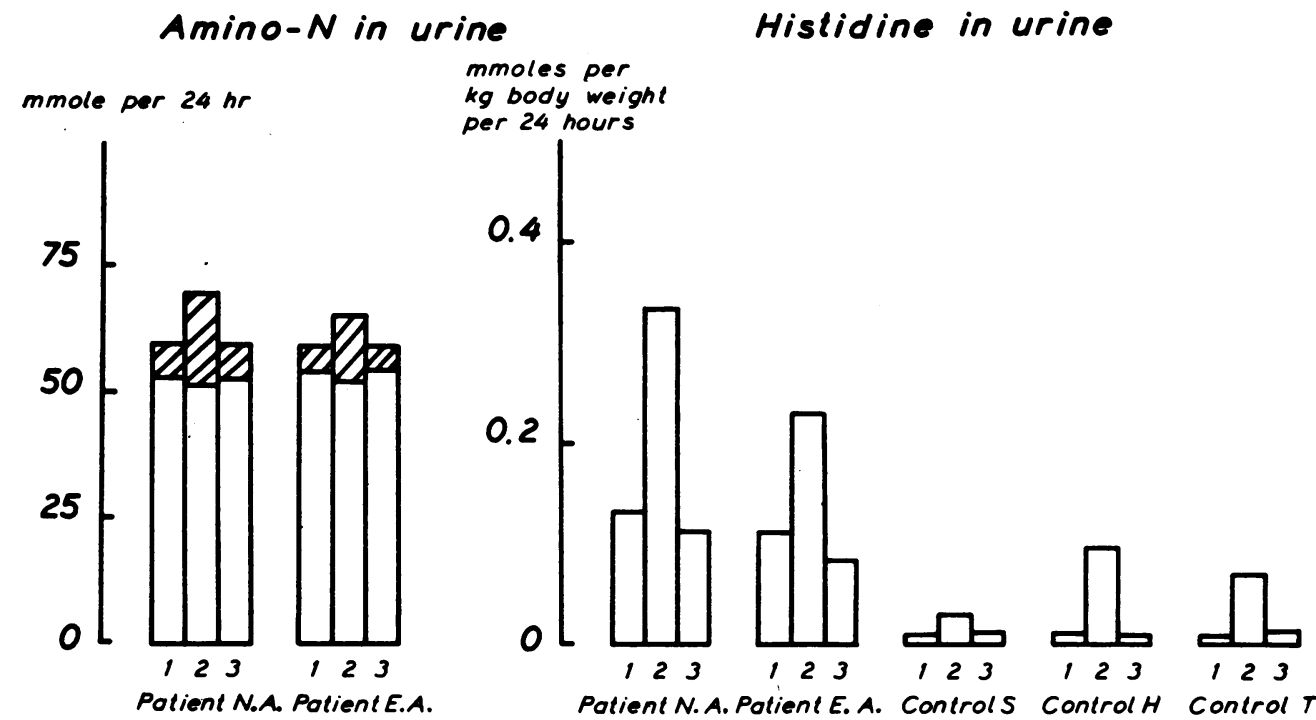

FIGURE 4 Urinary excretion of amino nitrogen and histidine in two patients with Hartnup disease before and after an oral load of 0.7 mmoles of L-histidine $/ \mathrm{kg}$ body weight: (1) Excretion on the day before; (2) on the day of the load; and (3) on the day after load. Closed bars represent the histidine part of the amino nitrogen. 
TABLE II

Intravenous Histidine Doses in Correlation to Body Weight and Exchangeable Body Water

\begin{tabular}{|c|c|c|c|c|c|c|}
\hline & \multicolumn{2}{|c|}{ Patients } & \multicolumn{4}{|c|}{ Controls } \\
\hline & E. A. & N. A. & A & B & $\mathrm{C}$ & $\mathrm{D}$ \\
\hline Body weight, $\mathrm{kg}$ & 51 & 57 & 70 & 80 & 73 & 68 \\
\hline Body length, $\mathrm{cm}$ & 170 & 160 & 180 & 178 & 176 & 185 \\
\hline Age, $y r$ & 15 & 19 & 25 & 21 & 38 & 31 \\
\hline \multicolumn{7}{|l|}{ Exchangeable body water } \\
\hline Observed, liter & 33.3 & - & 一 & 45.0 & 38.9 & 38.5 \\
\hline Calculated*, liter & 33.2 & - & - & 45.8 & 41.2 & 39.9 \\
\hline \multicolumn{7}{|l|}{ Dose L-histidine } \\
\hline mmole & 13.2 & - & 15.5 & 13.9 & 15.5 & 15.8 \\
\hline mmole/body wt & 0.26 & - & 0.22 & 0.17 & 0.21 & 0.26 \\
\hline mmole/exchangeable body water & 0.40 & - & - & 0.31 & 0.40 & 0.41 \\
\hline
\end{tabular}

* Calculated from the formula $\mathrm{EBW} / \mathrm{BW} \times 100=79.45-(0.2389 \times$ body wt $)-(0.1447 \times$ age $)(16)$.

amino nitrogen. The most characteristic features of the amino acid pattern were the high excretion of the essential amino acids and of glutamine, serine, histidine, and tyrosine (Fig. 1). The histidine excretion corresponded to about $60 \%$ (E. A.) and $75 \%$ (N. A.) of the histidine content of the food. The excretion of glycine and taurine was not noticeably increased and the excretion of aspartic acid, proline, cystine, and arginine was low, as in normal subjects. As revealed from twodimensional paper chromatograms, the output of asparagine, $\beta$-amino-iso-butyric acid, and 1- and 3-methylhistidine was normal.

The renal plasma amino acid clearance, calculated from the $24 \mathrm{hr}$ urinary excretion and from the fasting plasma level (Table I), was strikingly similar in the two patients (Fig. 2). There was apparently no, or a very small, tubular reabsorption of histidine, and the reabsorption of the essential amino acids, and of tyrosine, serine, and glutamine was markedly reduced. The reabsorption of glycine, taurine, proline, and arginine was normal. The fact that diurnal changes in the plasma amino acid levels were not taken into account can not have seriously influenced these results which are in agreement with results obtained in children with Hartnup disease $(14,15)$. The content of free amino acids in feces was somewhat higher in the patients than in controls $\mathrm{S}, \mathrm{H}$, and $\mathrm{T}$. However, judged from paper chromatograms, the total loss of free amino acids via feces was negligible, i.e., less than $1 \mathrm{mmole} /$ day. The fecal amino acid pattern was more variable from day to day than the urinary amino acid pattern in patients as well as in controls. The histidine content of feces was negligible in all samples.

Oral histidine loading. After oral histidine loading, a rapid and marked increase in the plasma histidine level was observed in the controls (Fig. 3), whereas in the patients there was only a small increase. Feces collected during the following days held only negligible amounts of histidine.

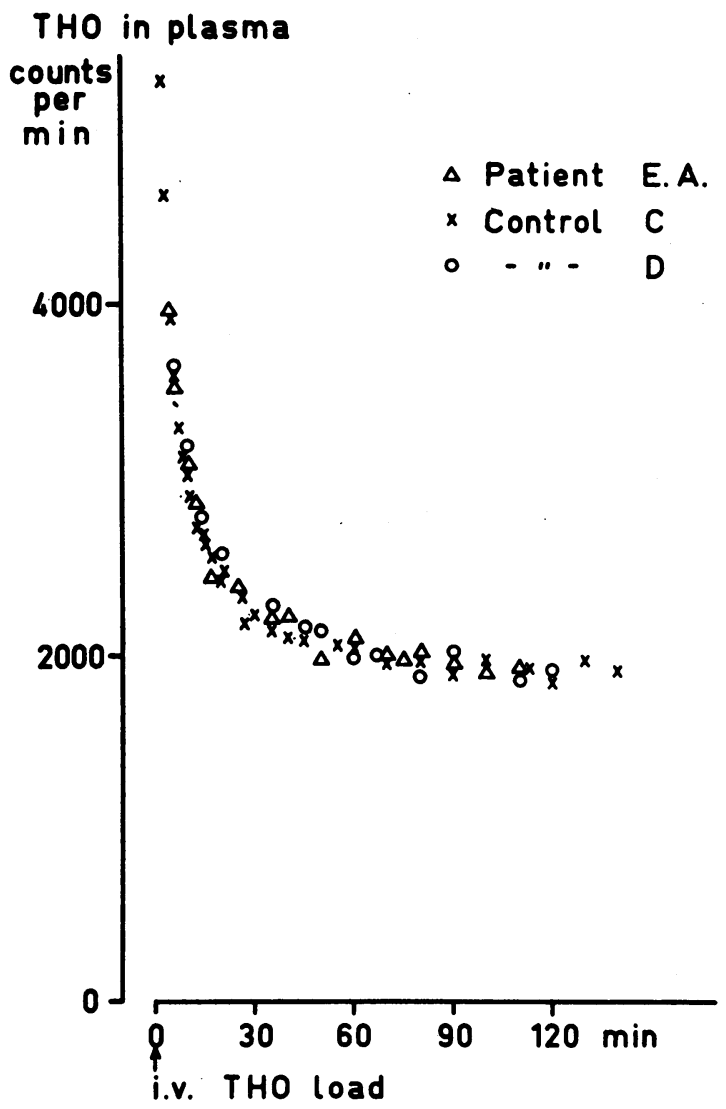

FigURe 5 Plasma radioactivity after single intravenous dose of tritium-labeled water and L-histidine to one patient with Hartnup disease and to two controls. The subjects were fasting $12 \mathrm{hr}$ before and during the test. 


\section{Histidine in plasma}

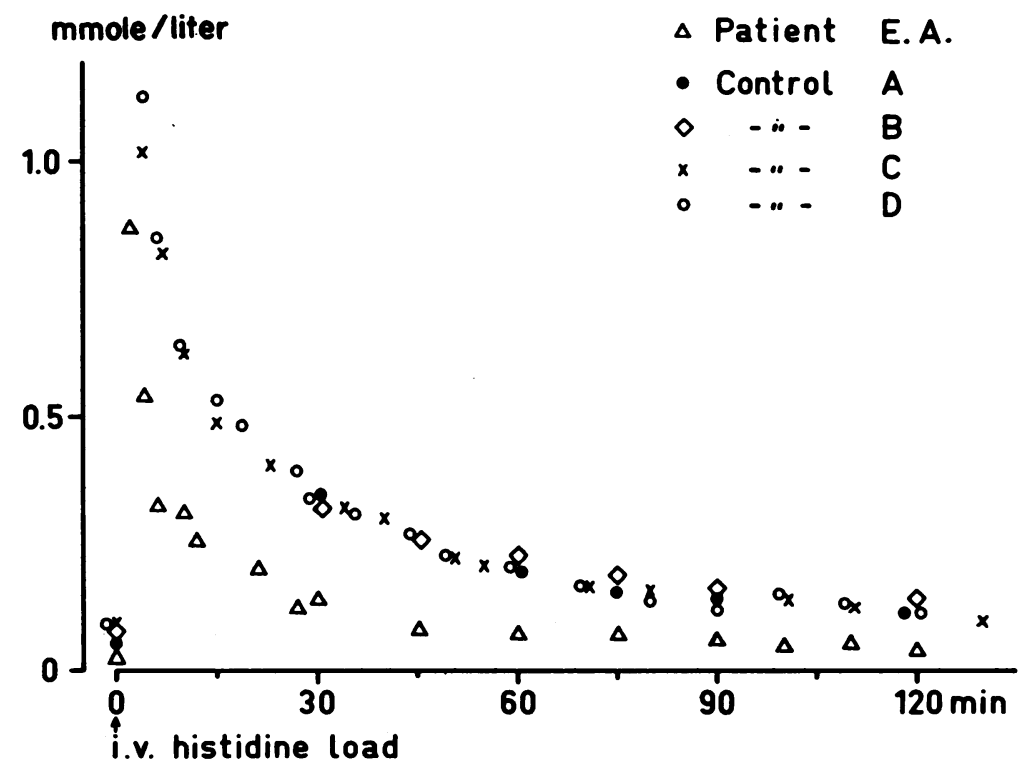

Figure 6 Plasma histidine level after single intravenous dose of tritiumlabeled water and L-histidine to one patient with Hartnup disease and to four controls. The histidine doses and data regarding the subjects are given in Table II. The subjects were fasting $12 \mathrm{hr}$ before and during the test.

The urinary excretion of free amino nitrogen in the two patients was higher on the day of the loading than on the day before and on the day after the loading (Fig. 4). This was entirely due to an increment in the histidine output. This increase in the urinary histidine output on the day of the loading corresponded to $32 \%$ of the oral dose in patient N. A. and to $19 \%$ in patient E. A. In the three controls, 2,11 , and $6 \%$, respectively, of the oral dose was recovered in the urine (Fig. 4).

Intravenous THO and L-histidine loading. The doses given and some data about the subjects are summarized in Table II. The exchangeable body water was normal in all subjects. The rate of elimination of tritium-labeled water from blood was identical in all subjects (Fig. 5). The elimination of the histidine dose from plasma was considerably faster in the patient than in the controls (Figs. 6 and 7), especially during the first few minutes. Thus, $6 \mathrm{~min}$ after the end of the injection the plasma histidine concentration was $325 \mu$ moles/liter in the patient and 822 and $850 \mu$ moles/liter in the controls, corresponding to $5 \%$ of the calculated concentration at zero time in the patient, and 16 and $17 \%$ in the controls. The histidine elimination curve appeared biphasic in a semilogarithmic diagrma (Fig. 7), and during the second phase the curve was essentially rectilinear. Calculated from the intercept of this slope the hypotetic histidine distribution volume was $93 \%$ of the exchangeable body water in the patient and 59 and $55 \%$ in the con- trols. During this phase the rate of elimination of histidine was $5.3 \%$ in the patient and 3.2 and $3.5 \%$ respectively in the controls.

The urinary histidine loss in the patient was considerable. Urine collected for $2 \mathrm{hr}$ before the loading held 0.47 mmoles of histidine (control C, 0.07 mmoles), and urine collected for $4 \mathrm{hr}$ after the loading contained 3.16 mmoles (control C, 0.18 mmoles). Thus in the patient $17 \%$ and in control $\mathrm{C}, 0.3 \%$ of the intravenously given dose was passed unchanged into the urine.

\section{DISCUSSION}

Milne (17) has set forth criteria for malabsorption of amino acids. He states that after ingestion of an amino acid there should be, when compared with controls, a lesser augmentation in the plasma concentration of the amino acid, more of the amino acid should appear in the feces, and finally, unusual bacterial strains may appear in the stools owing to an abnormal environment. The urinary loss of the amino acid, and the plasma concentration after intravenous loading should also be taken into consideration. After ingestion of L-histidine, the plasma histidine concentration in the patients increased much less than in the controls. This could indicate an incomplete or delayed absorption. However, the histidine loss via feces was negligible, in agreement with the results of Seakins and Ersser (18) and a large porportion of the oral histidine dose was recovered unchanged in 
the urine. Furthermore, when L-histidine was added to feces from the patients considerable amounts of histamine were formed (6). Provided the conditions in the feces reflect the intraluminal conditions in the gut, one would expect that an appreciable malabsorption of L-histidine would have led to marked increment in fecal histamine which was not observed (6). This fact is not in accordance with a major defect in the histidine absorption.

The effect of ingestion of an amino acid on the plasma level is not only due to the rate of absorption, but also to the rate of its elimination from the blood. The high renal clearance of histidine can only to a small extent explain the absence of a normal increase in the plasma histidine level after the oral loading. The elimination of histidine from plasma after the intravenous loading occurred in two main phases with different elimination rates. The first phase must essentially have been a dis-

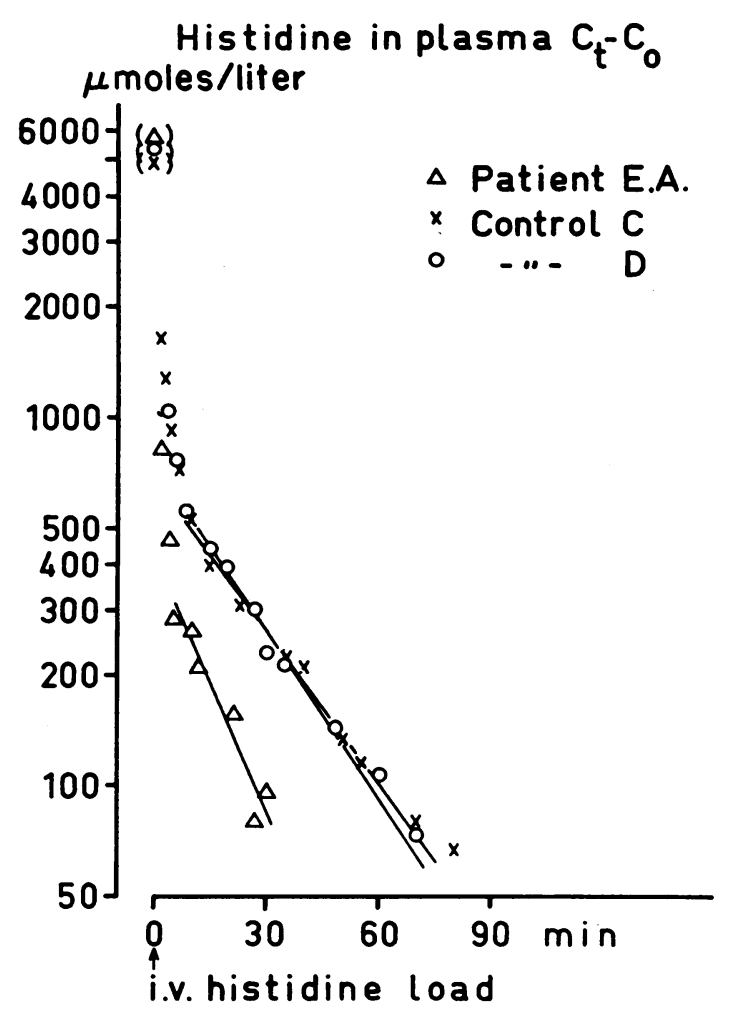

FIgURE 7 Elimination of histidine from plasma after single intravenous dose of tritium-labeled water and L-histidine to one patient with Hartnup disease and to two controls. On the ordinate the observed histidine concentration minus the concentration at zero time $\left(\mathrm{C}_{t}-\mathrm{C}_{0}\right)$ is given in a logarithmic scale. Further details see Fig. 6 . The regression lines, calculated by the method of least squares: Patient E. A.: $C=423 \cdot \mathrm{e}^{-0.063} \cdot \mathrm{t}$; Control $C$ : $C=684 \cdot \mathrm{e}^{-0.032} \cdot \mathrm{t}$; Control $\mathrm{D}$ : $\mathrm{C}=753 \cdot \mathrm{c}^{-0.035} \cdot \mathrm{t}$. The symbols in brackets indicate the calculated concentration at zero time $(100 \cdot$ histidine dose)/ (4.4 body weight $)$. tribution period, while the later phase reflected distribution, excretion, and metabolism. The great difference in elimination during the first few minutes after the load shows a faster distribution, i.e. a more rapid cellular uptake, in the patient than in the controls.

In rats the active intestinal absorption of histidine is increased after semistarvation (19). An analogous mechanism might explain the observed high disappearance rate of histidine from the blood in the Hartnup patient. The Hartnup patients had a constant heavy loss of histidine and of essential amino acids in the urine. On the controlled diet, they lost an amount of histidine in the urine equivalent to about two-thirds of the histidine supplied in the food. As the plasma amino acid levels were rather constant throughout the day a considerable outflow from intracellular pools must have taken place in the postabsorptive state. The heavy loss of histidine may have resulted in a low intracellular histidine pool corresponding to the condition of semistarvation in the rat (19). The rapid disappearance of histidine might thus be a compensatory reaction of normal histidinedeprived cells. The higher rate of disappearance of histidine in the patient than in the controls during the second phase, which reflected distribution, excretion, and metabolism, can only to a small extent have been due to the higher renal clearance in the patient. Conclusions cannot be drawn concerning differences in the metabolic rates of histidine from the results obtained.

The histidine absorption from the intestine does not seem to be obviously impaired in Hartnup disease. A rapid elimination from the blood seems to explain the lack of increase in plasma histidine after the oral loading. A somewhat delayed absorption, however, cannot be excluded as a contributory factor. The rapid disappearance from the blood is only to a small extent owing to the high renal clearance of histidine. A rapid cellular uptake of histidine explains the results obtained. A generally impaired cellular transport of L-histidine in Hartnup disease is thus improbable.

\section{ACKNOWLEDGMENT}

These studies were supported by a grant from the Swedish Research Council (Project No. B 67-13 X-652-03).

\section{REFERENCES}

1. Jepson, J. B. 1966. Hartnup Disease in The Metabolic Basis of Inherited Disease, J. B. Stanbury, J. B. Wyngaarden, and D. S. Fredrickson, editors. McGraw-Hill Book Company, New York. 2nd edition. 1283.

2. Asatoor, A. M., J. Craske, D. R. London, and M. D. Milne. 1963. Indole production in Hartnup disease. Lancet. 1: 126.

3. de Laey, P., C. Hooft, J. Timmermans, and J. Snoeck. 1964. Biochemical aspects of the Hartnup disease. Ann. Paediat. 202: 145.

4. Wong, P. W. K., and P. M. Pillai. 1966. Clinical and 
biochemical observations in two cases of Hartnup disease. Arch. Dis. Childhood. 41: 383.

5. Evered, D. F. 1956. The excretion of amino acids by the human: a quantitative study with ion-exchange chromatography. Biochem. J. 62: 416.

6. Sjaastad, O., and S. Halvorsen. 1968. Histaminuria in Hartnup disease. Acta Paediat. Scand. 57: 289.

7 Halvorsen, K., and S. Halvorsen. 1963. Hartnup disease. Pediatrics. 31: 29.

8. Spackman, D. H., W. H. Stein, and S. Moore. 1958. Automatic recording apparatus for use in the chromatography of amino acids. Anal. Chem. 30: 1190.

9. Stein, W. H., and S. Moore. 1954. The free amino acids of human blood plasma. J. Biol. Chem. 211: 915.

10. Jagenburg, O. R. 1959. The urinary excretion of free amino acids and other amino compounds by the human. Scand. J. Clin. Lab. Invest. 11 (Suppl.): 43.

11. Bray, G. A. 1960. A simple efficient liquid scintillator for counting aqueous solutions in a liquid scintillation counter. Anal. Biochem. 1: 279.

12. Vaugham, B. E., and E. A. Boling. 1961. Rapid assay procedures for tritium-labeled water in body fluids. $J$. Clin. Lab. Med. 57: 159.
13. Souci, S. W., W. Fachman, and H. Kraut. 1962. Die Zusammensetzung der Lebensmittel; Nährwert-Tabellen. Wissenschaftlich Verlagsgesellschaft $\mathrm{MBH}$. Stuttgart.

14. Wong, P. W. K., A. M. Lambert, P. M. Pillai, and P. M. Jones. 1967. Observations on nicotinic acid therapy in Hartnup disease. Arch. Dis. Childhood. 42 : 642.

15. Tada, K., H. Hirono, and T. Arakawa. 1967. Endogenous renal clearance rates of free amino acids in prolinuric and Hartnup patients. Tohoku J. Exp. Med. 93: 57.

16. Moore, F. D., K. H. Olesen, J. D. McMurrey, H. V. Parker, M. R. Ball, and C. M. Boyden. 1963. The Body Cell Mass and Its Supporting Environment. W. B. Saunders Company, Philadelphia. 159.

17. Milne, M. D. 1964. Disorders of amino acid transport. Brit. Med.J. 1: 327

18. Seakins, J. W. T., and R. S. Ersser. 1967. Effects of amino acid loads on a healthy infant with the biochemical features of Hartnup Disease. Arch. Dis. Childhood. 42: 682.

19. Kershaw, T. G., K. D. Neame, and G. Wiseman. 1960. The effect of semistarvation on absorption by the rat small intestine in vitro and in vivo. J. Physiol. 152: 182. 